\title{
Case-based Learning in Biochemistry: An Innovative Criterion-based Assessment Module for Effective Learning among MBBS Phase 1 Students in India
}

\author{
${ }^{1}$ Vijayetha P Patil, ${ }^{2}$ Vidya S Patil, ${ }^{3}$ Shrirang P Kulkarni, ${ }^{4}$ Dhiraj J Trivedi, ${ }^{5}$ Vani C Axita, ${ }^{6}$ Rakesh T Mudaraddi \\ ${ }^{7}$ Praveenkumar Shetty, ${ }^{8}$ Anil B Bargale, ${ }^{9}$ Pramod S Kamble, ${ }^{10}$ Deepti G Ingleshwar, ${ }^{11}$ AS Shilpasree
}

\begin{abstract}
Introduction: The main focus of case-based learning $(\mathrm{CBL})$ is to integrate basic science material with clinical science. Case-based learning may be designed and introduced along with traditional didactic lectures in a way that it creates interest, promotes better understanding, active participation, and selfdirected learning. The student should be motivated to become a life-long learner.
\end{abstract}

Intervention: We have formulated an innovative criterion-based module for implementation and evaluation of MBBS phase 1 students. This includes framing of a time schedule for distribution of teaching hours based on multiple teaching tools and module for conducting CBL sessions. This will be assessed by evaluation of student performance using a newly developed valid assessment tool.

Materials and methods: For the CBL sessions, 100 students of phase 1 MBBS course were included. They were divided into 10 groups of 10 students each. Ten clinical cases were selected for $\mathrm{CBL}$ sessions. Each student was given two cases for discussion. Pretest was conducted before and posttest after the CBL session. The session was conducted as planned in the module. The performance of the students was analyzed. Feedback from the students and teachers were taken and analyzed for its utility and effectiveness.

Results: The performance of the students showed drastic improvement after the CBL sessions ( $p<0.0001$ ); $85 \%$ of the students and $80 \%$ of the teachers agreed that CBL helps in deep learning and critical thinking; $84 \%$ of students and $73 \%$ teachers felt that $\mathrm{CBL}$ makes subject interesting with good retention of contents and reasoning ability for their future medical practice.

Conclusion: Our newly formulated assessment tool stands appropriate, which can be included in the present curriculum. Both the teachers and the students were satisfied with this kind of teaching method. This innovative teaching module and our newly formulated assessment tool proved to be very effective for learning biochemistry.

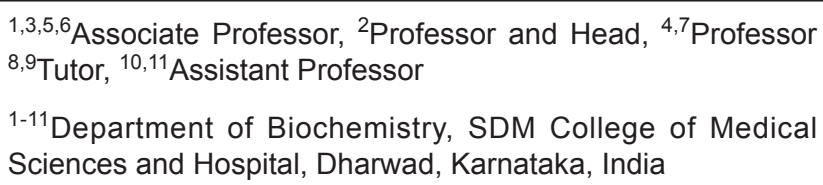

Corresponding Author: Shrirang P Kulkarni, Associate Professor, Department of Biochemistry, SDM College of Medical Sciences and Hospital, Dharwad, Karnataka, India Phone: +919448187034, email: drsrirang@gmail.com
Keywords: Assessment tool, Biochemistry, Case-based learning, Critical thinking, Curriculum planning, Multiple teaching tools, Structured cases, Student feedback, Teacher's reflections, Teaching module.

How to cite this article: Patil VP, Patil VS, Kulkarni SP, Trivedi DJ, Axita VC, Mudaraddi RT, Shetty P, Bargale AB, Kamble PS, Ingleshwar DG, Shilpasree AS. Case-based Learning in Biochemistry: An Innovative Criterion-based Assessment Module for Effective Learning among MBBS Phase 1 Students in India. Indian J Med Biochem 2017;21(1):62-68.

\section{Source of support: Nil}

Conflict of interest: None

\section{INTRODUCTION}

Biochemistry is one of the basic science subjects in the first phase of medical curriculum. In the present day scenario, didactic lectures are the mainstay of teaching biochemistry in most of the medical schools in India. Such a system is teacher-centered with minimal active participation from the students. ${ }^{1}$ Teaching the basic science subjects is very important for the clinical years that lie ahead. ${ }^{2}$ Recently, a series of strategies and alternatives are developing for teaching biochemistry. There is a continued need for the development of alternatives to expand learning styles and making it more interesting and fun to learn and study rather than making it boring. Case-based learning (CBL) may be designed and introduced along with traditional didactic lectures in a way that it creates interest, promotes better understanding, active participation and self-directed learning. As a whole, learning should be made a pleasure and the student should be motivated to become a life-long learner.

Emerging trend all over the world today is to have a problem-based or case-based student-centered medical curriculum, demanding active participation from the students and facilitating self-directed learning. Many authors are convinced that students learn more effectively if the knowledge and skills they acquire are inserted and contextualized in relevant real-life, problem-based situations. ${ }^{3}$ Problem-based learning (PBL) was first introduced by McMasters University medical school as an educational format centered around the discussion, and 
learning that emanates from a clinically based problem. ${ }^{4}$ In PBL, students use a trigger for a problem to define their own learning objective, which requires ability to process and discuss ideas and learn independently. Problembased learning in its original format of "open inquiry approach" may not be possible in our setup because students entering MBBS course are coming from a regular way of teaching where they are exposed to only didactic lectures. There is no prior exposure toward self-directed learning and active participation. ${ }^{4,5}$ Thus, there is a need for gradual change in the teaching and learning program where formal way of teaching has to continue and the newer approaches have to be introduced along with.

Case-based learning is an educational paradigm closely related to the PBL that uses a "guided inquiry approach" toward solving the problem. ${ }^{5}$ Case-based learning main traits are derived from PBL. Case-based learning provides more structure during small group discussions. Cases place events in a context or situation that promote authentic learning and allow students to develop a collaborative team-based approach to their education. The other benefits of CBL are that it develops intrinsic and extrinsic motivation for learning, encourages self-evaluation and critical reflection, integrates knowledge and practice, and helps to develop learning skills. ${ }^{6}$ Teachers would also benefit from taking CBL to their teaching as they have a chance to reflect upon the learning process when they formulate and introduce the cases to students.?

The main focus of CBL is to integrate basic science material with clinical science. We have to mainly focus on the way by which we can implement this CBL approach along with the traditional curriculum and also evaluate it in a proper way, so that it can be reflected on as a better learning tool. Thus we have formulated a simple innovative module for implementation and evaluation of CBL as a tool to teach biochemistry for MBBS phase 1 students.

\section{OBJECTIVES}

- To develop an additional simple teaching module with the existing university curriculum to improve the clinical applicability of biochemistry

- To develop an assessment module in view of assessment of student's skills to interpret and identify the clinical problem
- To evaluate the utility and effectiveness of the new teaching and assessment module

\section{INTERVENTION}

\section{Module for Implementation}

To meet the above objective, we formulated an innovative module for implementation and evaluation of phase 1 MBBS students.

\section{Simple Teaching Module including CBL Sessions}

1. Distribution of teaching hours based on multiple teaching tools

The teaching hours include didactic lectures, tutorials, practicals, demonstrations, and case discussions (Table 1).

2. Conducting CBL sessions

(a) Selection of cases was based on real-life problems and in alignment with the curricular material previously covered.

Cases are selected based on the topics going on simultaneously in theory classes. Theory classes will provide the core content of the subject and also creates a link with the case to be discussed. One module covering the overall concept of related topics that can lead the students toward clinical application of biochemistry is shown in Table 2.

(b) Structuring of cases - based on the requisites ${ }^{8}$ The cases which are formulated:

- Stimulate thinking, analysis, and reasoning

- Stimulate self-directed learning

- Promote studying the intended contents

- Enhance interest in subject matter

- Have relevance to the future profession with realistic content

- Match the level of prior knowledge

(c) Pattern of case discussions

\section{Pattern of case discussions (Newly formulated module)}

This is based on the aim that the learning context should closely match the situations in which the information will be utilized and should improve the

Table 1: Proposed teaching hours: Based on multiple teaching tools for 1 year (newly formulated module)

\begin{tabular}{llll}
\hline Teaching method & No. of hours (weekly) & Total no. of hours & No. of classes \\
\hline Lectures & 4 (regular) & 120 & 120 classes \\
Practicals & 2 (alternate with tutorials) & 40 & 20 classes \\
Tutorials & 2 (once in 3 weeks) & 20 & 10 classes \\
Demonstrations & At the end of 1 year & 10 & 5 classes \\
Case discussions & 2 (regular) & 64 & 32 classes \\
Exams and holidays & & $4-6$ weeks \\
\hline
\end{tabular}


Table 2: Selection of cases based on topics covered in lectures: Newly formulated module

\begin{tabular}{|c|c|c|}
\hline Period & Topic in theory classes & Case discussions \\
\hline \multirow[t]{5}{*}{1 st $-1-3$ months } & Protein chemistry, plasma proteins & Multiple myeloma \\
\hline & Hemoglobin & Porphyria, thalassemia, sickle cell anemia \\
\hline & Enzymes & Diagnostic enzymology - myocardial infarction, acute pancreatitis \\
\hline & Liver function tests & Hemolytic jaundice, hepatic jaundice, obstructive jaundice, fatty liver \\
\hline & Fat-soluble vitamins & Vitamin A deficiency, rickets, osteoporosis \\
\hline \multirow[t]{3}{*}{ 2nd - 3-6 months } & Carbohydrates and lipids & $\begin{array}{l}\text { Glucose tolerance test charts, galactosemia, Von Gierke's disease, } \\
\text { diabetic ketoacidosis, dyslipidemia, etc. }\end{array}$ \\
\hline & Proteins, inborn errors of metabolism & $\begin{array}{l}\text { Phenylketonuria, alkaptonuria, maple syrup urine disease, Tay- } \\
\text { Sachs disease, etc. }\end{array}$ \\
\hline & Water-soluble vitamins & Beri beri, pellagra, scurvy, etc. \\
\hline \multirow[t]{5}{*}{$3 r d-6-9$ months } & Minerals & Iron deficiency anemia, Wilson's disease, goiter, etc. \\
\hline & Nutrition & Kwashiorkor, marasmus, obesity \\
\hline & Acid/base balance & Acidosis and alkalosis (metabolic and respiratory) \\
\hline & Thyroid & Hypo- and hyperthyroidism, cretinism \\
\hline & Renal & Renal failure, glomerulonephritis, nephrotic syndrome \\
\hline
\end{tabular}

understanding, participation, and analytical knowledge of the students.

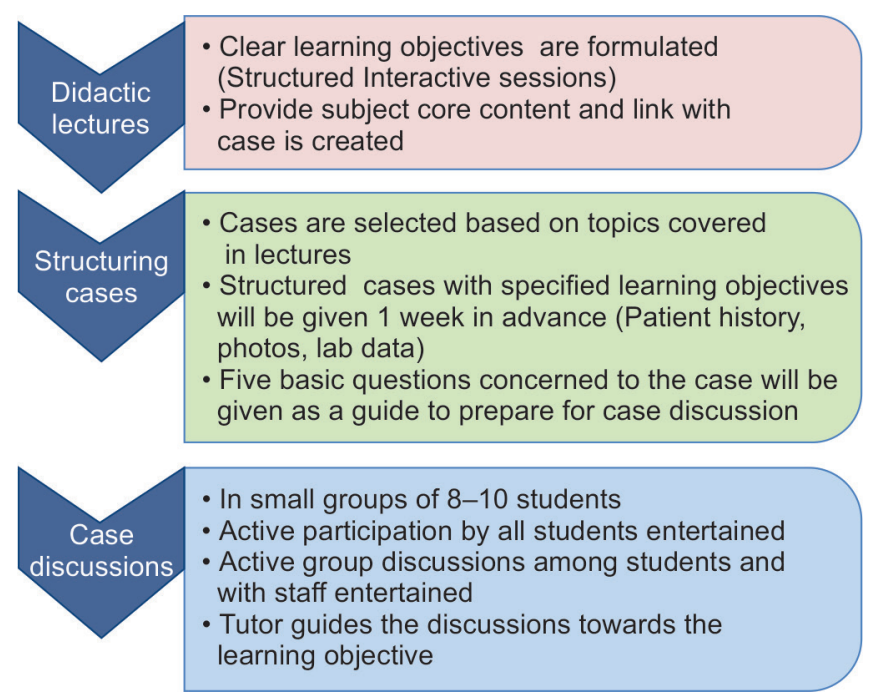

- Simulated cases were shown to the students in groups

- Clinical pictures were shown as power point slides

- Biochemical basis of the disorder in relation to the normal processes was highlighted before summarizing the case

- Clarifications and explanations were given regarding

- Biochemical basis of disorder

- Biochemical basis of clinical features

- Biochemical basis of abnormal lab tests

- Other clinical features, lab tests in support of diagnosis

- Complications and treatment in short wherever required

- Handouts of summary were given at the end

\section{Evaluation of Student Performance}

- Formative assessment testing the knowledge gained by the students
- Case-based exams followed by newly formulated module for assessment of student's skills in interpreting the case

- To assess knowledge base, clinical reasoning, and decision-making skills (Table 3). This module was tested for its reliability, validity, feasibility, acceptability, and educational impact.

The evaluation pattern will be discussed in detail among the teachers before starting the CBL sessions.

\section{Utility and Effectiveness of New Teaching Module}

- It can be evaluated by comparing the performance levels of students exposed to traditional way of teaching and those exposed to the new modified CBL module.

- Student's perceptions - Retrospective survey can be done using questionnaire..$^{9-11}$

- Teacher's reflections - Survey using questionnaire. ${ }^{11}$

\section{MATERIALS AND METHODS}

\section{Prior to the Case-based Learning Session}

Before starting this kind of innovative CBL sessions, we prepared a questionnaire to know the teacher's perceptions on the new teaching module described above. The details of the module were described in detail to all the teachers. Feedback was taken from each subject expert in the college regarding the new module of teaching, which was then validated by the experts. Informed consent was taken from the students and ethical clearance obtained from the Institutional Ethical Committee.

\section{During the Session}

Study participants: Hundred students studying in the phase 1 MBBS course were included for the CBL sessions; 87 students participated in the study. 
Table 3: Course end examination: Evaluation of students' skills in interpreting the case: Newly formulated module

(To assess knowledge base, clinical reasoning, and decision-making skills)

\begin{tabular}{lcc}
\hline Question & Score & 0 \\
\hline Is the student able to attribute the case to correct system/organ/metabolic dysfunction? & 1 & 2 \\
Is the student able to pinpoint/identify the important clinical feature/lab finding? & 0 & 1 \\
Is the student able to explain the normal functions/normal metabolic roles related to the system/organ & 0 & 2 \\
dysfunction? & 0 & 1 \\
Is the student able to associate the key clinical/lab finding with system/organ/metabolic dysfunction? & 0 & 2 \\
Is the student able to associate other clinical findings given with the problem? & 0 & 1 \\
Is the student able to associate other lab findings given with the problem? & 0 & 1 \\
Is the student able to explain the clinical problem with its biochemical basis? & 0 & 1 \\
Is the student able to suggest other lab investigations in support of diagnosis? & 2 \\
Is the student able to narrate other clinical features associated with the condition and its complications? & 0 & 1 \\
Is the student able to tell about the treatment of the disease/differential diagnosis? & 0 & 1 \\
Total eligible score & 2 \\
Skill/Performance level (Poor/Average/Good/Very Good/Excellent) & 2
\end{tabular}

Score: 0 - Not able to answer anything correctly

1 - Answers correctly but not completely $(<75 \%)$

2 - Answers correctly and completely $(>75 \%)$

Levels of eligibility to answer:

Level-1: Q 1, 2 - Students should answer at least 1 question correctly to go to second level

Level-2: Q 1, 2, 3, 4, 5 - Students should answer at least 1 question correctly among Q 1, 2 and at least 2 among Q 3, 4, 5 to go to next level

Level-3: Q 1, 2, 3, 4, 5, 6, 7, 8 - Students should answer at least 3 questions correctly among Q 1, 2, 3, 4, 5 and at least 2 among Q $6,7,8$ to go to next level

Level-4: Q 1, 2, 3, 4, 5, 6, 7, 8, 9, 10 - Students are eligible to answer all 10 questions

If the requisites are not met, then the questions answered above the eligible level will automatically stand cancelled and will not be considered for scoring.

\begin{tabular}{ll}
\hline Skill/performance level & Total eligible score (20) \\
\hline Poor & $0-2$ \\
Average & $3-6$ \\
Good & $7-11$ \\
Very good & $12-16$ \\
Excellent & $17-20$ \\
\hline
\end{tabular}

Table 4: Comparison of results of the pretest and posttest by Student's paired t-test

\begin{tabular}{llll}
\hline & Pretest score $(n=87)$ & Posttest score $(n=87)$ & $<0.0001^{*}$ \\
\hline Pretest-posttest & $4.9 \pm 2.9$ & $12.1 \pm 3.9$ & $<$
\end{tabular}

${ }^{*} p<0.0001$ highly significant; values expressed as mean \pm standard deviation

The pattern was followed as per the module formulated and mentioned above. The topic was taught in the classroom in the form of didactic lecture. We then divided the students into 10 batches of 10 students each. Ten clinical cases were selected for CBL sessions. Each student was given two cases for discussion. Pretest was conducted before the actual CBL sessions in the standard format of questions according to our criterion-based module. The CBL sessions were conducted as described in the section above. We discussed the same topic in small groups of 10 students with detailed discussion and clarification of the student's doubts, followed by posttest for CBL session.

\section{After the Case-based Learning Session}

The answer scripts were evaluated as per the newly formulated assessment tool (Table 3) and the performance of the students was analyzed. The marks obtained by the students in the pretest and posttest were tabulated and analyzed by Student's paired t-test using Statistical Package for the Social Sciences software version 20. Feedback was taken from the students regarding this module using a prevalidated questionnaire and was analyzed. Teacher's reflections on CBL sessions were also taken using a prevalidated questionnaire and analyzed.

\section{RESULTS}

The performance of the students showed drastic improvement after the CBL sessions (Table 4). There was highly significant improvement in their marks. The performance level of the students was average before the CBL sessions (pretest scores), which later improved to very good level after the CBL session (posttest scores) 
Table 5: Students feedback for CBL sessions: Evaluation of utility and effectiveness of case-oriented learning (modified approach)

\begin{tabular}{|c|c|c|c|c|c|}
\hline \multirow[b]{2}{*}{ Questions } & \multicolumn{5}{|c|}{ Responses in \% } \\
\hline & 1 & 2 & 3 & 4 & 5 \\
\hline \multicolumn{6}{|l|}{ Knowledge score } \\
\hline Useful in structuring the basic knowledge for use in clinical context & 76 & 6 & 16 & 2 & 0 \\
\hline Improves the critical thinking and reasoning skills & 80 & 5 & 14 & 1 & 0 \\
\hline Improves in deep learning & 81 & 6 & 12 & 1 & 0 \\
\hline \multicolumn{6}{|l|}{ Attitude score and professionalism } \\
\hline Useful in initiating the self-directed learning skills & 74 & 7 & 15 & 4 & 0 \\
\hline Increases the motivation for learning & 71 & 8 & 19 & 2 & 0 \\
\hline Promotes self-confidence & 65 & 11 & 20 & 4 & 0 \\
\hline Helps to improve communicating skills & 62 & 13 & 19 & 6 & 0 \\
\hline \multicolumn{6}{|l|}{ Satisfaction score } \\
\hline Promotes meaningful learning & 82 & 6 & 9 & 3 & 0 \\
\hline Promotes the active learning process & 71 & 4 & 23 & 2 & 0 \\
\hline Makes the subject interesting and understandable & 83 & 9 & 7 & 1 & 0 \\
\hline \multicolumn{6}{|l|}{ Utility score } \\
\hline Helps to retain the content of biochemistry rather than memorizing the facts & 79 & 4 & 14 & 3 & 0 \\
\hline Structured didactic lectures before case studies help in better understanding & 81 & 8 & 7 & 4 & 0 \\
\hline Helps to prepare for university annual examination & 76 & 6 & 10 & 8 & 0 \\
\hline \multicolumn{6}{|l|}{ Perceptions on CBL sessions } \\
\hline Cases were realistic and open ended for adequate discussion & 72 & 12 & 15 & 1 & 0 \\
\hline Cases were in alignment with the curricular material previously covered & 69 & 14 & 17 & 0 & 0 \\
\hline Evaluation system is fair in assessing each student's performance & 75 & 10 & 14 & 1 & 0 \\
\hline
\end{tabular}

1 - Totally agree, 2 - Agree, 3 - Neutral, 4 - Disagree, 5 - Totally disagree

$(\mathrm{p}<0.0001)$, which was assessed based on the new assessment module.

The majority of student feedback in relation to their CBL experiences was very positive; $85 \%$ of the students agreed that CBL helps in deep learning and critical thinking, reasoning, and diagnostic interpretation, which improved their knowledge; $77 \%$ of them agreed that it helps in self-directed learning, improves confidence and communication skills; $85 \%$ were highly satisfied with this kind of learning sessions that made the subject more interesting and enjoyable; $84 \%$ felt it will help in their preparation for exams and content retention for their future. The feedback is summarized in Table 5 .

The teachers also gave their reflections and feedback which is summarized in Table $6 ; 80 \%$ of the teachers agreed that CBL will help in deep learning and better understanding of the subject; $40 \%$ agreed that it will improve their communication skills and active participation; $60 \%$ agreed totally that it will help to retain the content and perform better in exams but it takes time for preparation by the teachers; $73 \%$ agreed that as the cases are based on real-life problems, it will help them in their future profession; $56 \%$ agreed regarding the assessment of the students based on this new module.

\section{DISCUSSION}

In the traditional curriculum, learning is teacher-centered. The teacher has the responsibility to teach, and took the responsibility for what was to be learned by the students. Lack of clinical relevance to learning will make the subject disinteresting and boring to them and learn biochemistry by rote memorization. ${ }^{12}$

This new CBL module is designed in such a way that it can be implemented with much ease along with the existing pattern of curriculum. Here the clinical correlations start from the beginning of the course in alignment with the topics covered in lectures. By this approach, students will be able to retain the knowledge through active participation rather than rote memorization, develop reasoning strategies, and assume responsibility for learning. In addition, they develop problem-solving skills, clinical judgment, and self-assessment skills and practice applying biochemical knowledge to clinical practice. Use of multiple teaching tools will provide a broad understanding of the subject without any drastic change in teaching pattern. The students accepted the newer ways of teaching and learning with greater interest and involvement.

Cases helped learners to develop problem-solving skills and collaborative skills that are recognized as key outcome skills that students will need in their future professional lives. Structured cases were given to the students for small group discussions. The group focused on creative problem-solving with some advance preparation. The facilitators/tutors will use guiding questions to bring them onto the main learning objective. Both students and faculty contribute to the discussion; learning issues are preidentified while student discussion is still 
Case-based Learning in Biochemistry

Table 6: Teachers' reflections on CBL

\begin{tabular}{|c|c|c|c|c|c|}
\hline \multirow[b]{2}{*}{ Questions } & \multicolumn{5}{|c|}{ Responses in \% } \\
\hline & 1 & 2 & 3 & 4 & 5 \\
\hline \multicolumn{6}{|l|}{ Knowledge score } \\
\hline CBL helps to increase students interest in biochemistry & 20 & 70 & 10 & 0 & 0 \\
\hline CBL helps in deep learning & 10 & 70 & 20 & 0 & 0 \\
\hline CBL improves clinical reasoning abilities & 20 & 60 & 20 & 0 & 0 \\
\hline CBL improves analytical skills & 30 & 40 & 30 & 0 & 0 \\
\hline \multicolumn{6}{|l|}{ Attitude and professionalism } \\
\hline CBL improves communication skills & 0 & 60 & 40 & 0 & 0 \\
\hline CBL improves peer interaction & 0 & 30 & 60 & 10 & 0 \\
\hline $\mathrm{CBL}$ improves attendance and active participation & 10 & 20 & 60 & 10 & 0 \\
\hline \multicolumn{6}{|l|}{ Utility score } \\
\hline CBL helps students to prepare and perform better in course end examinations & 10 & 30 & 60 & 0 & 0 \\
\hline $\mathrm{CBL}$ helps to retain the content of biochemistry rather than rote memorization & 10 & 60 & 30 & 0 & 0 \\
\hline CBL helps in better understanding & 10 & 70 & 20 & 0 & 0 \\
\hline CBL needs more time for preparation by the staff & 20 & 40 & 40 & 0 & 0 \\
\hline CBL needs more time for preparation by the student & 0 & 50 & 20 & 30 & 0 \\
\hline \multicolumn{6}{|l|}{ Perceptions on $C B L$} \\
\hline Criterion-based structuring of cases was ideal and real-life based & 10 & 50 & 40 & 0 & 0 \\
\hline Cases discussed have clear linkage with the future profession of students & 40 & 60 & 0 & 0 & 0 \\
\hline $\begin{array}{l}\text { Regular assessment in CBL sessions is ideal to evaluate the overall improvement in } \\
\text { individual student's attitude toward learning as a whole }\end{array}$ & 0 & 60 & 40 & 0 & 0 \\
\hline \multicolumn{6}{|l|}{ Perception on assessment } \\
\hline $\begin{array}{l}\text { Criterion-based summative assessment of case studies is ideal to assess the knowledge } \\
\text { gained by the student }\end{array}$ & 10 & 30 & 60 & 0 & 0 \\
\hline Peer assessment helps us to give positive feedback to students for their improvement & 0 & 40 & 50 & 10 & 0 \\
\hline Students' self-assessment will help them to improvise their learning abilities & 10 & 80 & 10 & 0 & 0 \\
\hline
\end{tabular}

1 - Totally agree, 2 - Agree, 3 - Neutral, 4 - Disagree, 5 - Totally disagree

promoted. ${ }^{13}$ Mean score of knowledge acquisition was higher in student exam results when facilitated by expert tutors compared with nonexperts ${ }^{14}$ and our study also showed the same results (Table 4 ). The guidance given by the expert will take away the fear of active participation in discussion, encourages students to search literature for information, and allows the student to understand the concept with much ease.

Students undertaking CBL format were encouraged to ask questions and make comments during class and CBL made the learning more enjoyable compared with traditional lecture format. Student's perception indicated that clinical reasoning, diagnostic interpretations, and the ability to think logically were also improved with CBL. ${ }^{5,15}$ This study showed that students performed better in post CBL sessions, indicating CBL is an effective method compared to didactic lectures that helped the students in deep learning ${ }^{16,17}$ (Table 4). The deep approach is the most appropriate and desirable way of learning, i.e., closely linked to the intellectual processes that are expected in all medical students. ${ }^{18}$ The CBL not only integrated the related basic sciences and clinical medicine but also importantly linked to student's developing knowledge of theory into practice. Case-based learning was also valued by students as their first introduction to clinical skills, with most tutors believing that it was the nonthreatening environment that helped students gain confidence for their first "real patient" encounters. ${ }^{19}$

Traditional forms of assessments are not compatible with the overall constructivist nature of the case-based approach of learning and teaching. Poorly designed assessment has the danger of wrongly focusing student's attention onto surface learning skills, such as rote memorization. Since assessment drives learning, learning process also should be included in the assessment scheme; otherwise it de-emphasizes the process elements like problem-solving skill, teamwork, and communication. ${ }^{20}$

Our newly formulated assessment module for CBL sessions focuses on the learning of the students. The questions asked about a particular problem start from basic information toward critical thinking and reasoning. The way in which different levels of eligibility are created drives the student learning in a deep manner rather than rote memorization. Valuation of the answer scripts were made more objective by formulating specific questions which satisfies the specific learning objectives and giving answer keys to the teachers. This made the assessment more valid. Performance by the students was consistently very good in all CBL sessions, even when different cases were given to different groups. This makes it more 
reliable. Students are strongly influenced by assessment. According to the feedback given by the students and teachers, this module has a good educational impact. The time and effort taken for formulating and testing this new module of teaching was worth it, and we found it to be practical and feasible. Hence, our newly formulated assessment tool stands appropriate, which can be included in the present curriculum. ${ }^{21}$

The utility and effectiveness of this new teaching module has been proven by analyzing the student's performance in formative assessment. Feedback from students gave us the final result of success of this teaching module ${ }^{22}$ (Table 5) and also teacher's reflection toward improvements in the teaching learning process (Table 6). Both the teachers and the students were satisfied with this kind of teaching method. ${ }^{23}$ This innovative teaching module and our newly formulated assessment tool proved to be very effective for learning biochemistry.

\section{Implications of the Proposed Teaching Learning Module}

- Implementation of this modified approach toward case studies will improve the student's exposure to clinical cases while learning basic concepts and also understanding of the subject with a friendlier and acceptable attitude.

- By making it a regular teaching tool from the beginning, it will help students to improvise their thinking ability in applying basic knowledge to analyze and interpret the clinical problem and also appropriate utilization of the lab tests toward diagnosis and prognosis of the clinical scenario.

To conclude, the focus of the present study was to design a simplified CBL course and assessment strategies directed toward our learning objectives. Hence, we have formulated an innovative simple CBL session along with few new modules for assessment and few modified from literature. We implemented it in our existing curriculum without much requirements of additional infrastructure or teaching faculty. We also saw very good outcome of this teaching module. These modules can be implemented and any improvements needed may be introduced in future.

\section{REFERENCES}

1. Supraneni KM. The effect of integrated teaching with case based learning (CBL) in the biochemistry of undergraduate medical curriculum. J Clin Diagn Res 2010;5:3058-3063.

2. Badyal DK, Singh T. Teaching of the basic sciences in medicine: changing trends. Natl Med J India 2015 May-Jun;28(3):137-140.

3. Alexandre B, Passos RM, Ono AH, Hermes-Lima M. The use of multiple tools for teaching medical biochemistry. Adv Physiol Educ 2008;32(1):38-46.

4. Ghosh S. Combination of didactic lectures and case-oriented problem-solving tutorials toward better learning: perceptions of students from a conventional medical curriculum. Adv Physiol Educ 2007 Jun;31(2):193-197.

5. Setia S, Bobby Z, Anantanarayan P, Radhika M, Kavitha M, Prashanth T. Case based learning versus problem based learning: A direct comparison from first year medical students perspective. Med Educ 2011;2(6):WMC001976.

6. Williams B. Case based learning - a review of the literature: is there a scope for this educational paradigm in prehospital education? Emerg Med J 2005 Aug;22(8):577-581.

7. Harrington HL, Quinn-Lerring K, Hodson L. Written case analyses and critical reflection. Teaching Teacher Educ 1996;12(1):25-37.

8. Munshi FM, El Zayat EA, Dolmans DH. Development and utility of a questionnaire to evaluate the quality of PBL problems. South East Asian J Med Educ 2008;2(2):32-40.

9. Elizondo-Montemayor LL. Formative and summative assessment of the problem based learning tutorial session using a criterion-referenced system. Int Assoc Med Sci Educators 2004;14(1):8-14.

10. Blewett EL, Kisamore JL. Evaluation of an interactive, casebased review session in teaching medical microbiology. BMC Med Educ 2009 Aug 27;9:56.

11. Ciraj AM, Vinod P, Ramnarayan K. Enhancing active learning in microbiology through case based learning: experiences from an Indian medical school. Indian J Pathol Microbiol 2010 Oct-Dec;53(4):729-733.

12. Surlekar S. Teaching biochemistry in a 'Guided Discovery Curriculum'. Biochem Educ 1998;26(3):218-222.

13. Srinivasan M, Wilkes M, Stevenson F, Nguyen T, Slavin S. Comparing problem-based learning with case-based learning: effects of a major curricular shifts at two institutions. Acad Med 2007;82(1):74-82.

14. Hay P, Katsikitis M. The 'Expert' in problem-based and casebased learning: necessary or not? Med Educ 2001 Jan;35(1):22-26.

15. Kassebaum D, Averbach R, Fryer G. Student preference for a case-based vs. lecture instructional format. J Dent Educ 1991 Dec;55(12):781-784.

16. Nair SP, Shah T, Seth S, Pandit N, Shah GV. Case based learning: a method for better understanding of biochemistry in medical students. J Clin Diagn Res 2013 Aug;7(8):1576-1578.

17. Joshi KB, Nilawar AN, Thorat AP. Effect of case based learning in understanding clinical biochemistry. Int J Biomed Adv Res 2014;5(10):516-518.

18. Adiga U, Adiga S. Case based learning in biochemistry. Int J Pharm Biosci 2011;2(2):332-336.

19. Hudson JN, Buckley P. An evaluation of case-based teaching: evidence for continuing benefit and realisation of aims. Adv Physiol Educ 2004 Dec;28(1-4):15-22.

20. McNaught C, Lam P, Ong D, Lau L. Challenges in assessments in a case based science course. In: Frankland F, editor. Enhancing teaching and learning through assessment: deriving and appropriate model. Dordrecht: Springer; 2007. p. 256-264.

21. Sood R, Singh T. Assessment in medical education: evolving perspectives and contemporary trends. Natl Med J India 2012;25(6):357-364.

22. Salgar ST. Case based learning: an innovative student-centred methodology for teaching biochemistry. Int J Biomed Res 2014;5(1):25-27.

23. Thistlthwaite JE, Davies D, Ekeocha S, Kidd JM, MacDougall C, Matthews P, Purkis J, Clay D. The effectiveness of case-based learning in health professional education. A BEME systematic review: BEME Guide No. 23. Med Teach 2012;34(6):e421-e444. 